THURSDAY, JULY I6, 1874

\section{SCIENCE IN THE SHOWYARD}

$T^{T}$ is difficult to over-estimate the benefits which prac1 tical agriculture has derived from the great country meetings of our Agricultural Societies. Shifting from year to year to different parts of England these annual exhibitions have brought the general progress of agriculture to bear in a direct manner upon local practice, and made the country farmer acquainted with the improvements that have originated in distant centres of activity; while at the same time the peculiar excellences of the district visited are prominently brought to light, and give their own distinctive character and teaching to the exhibition. The beneficial influence of such Agricultural Shows is much increased when, as in the case of the show now being held at Bedford, they are conducted by a first-class Society. Not only are the exhibitions in this case of greater number, and superior quality, but the character of the judging is superior also, and science is really brought to bear in awarding the prizes in the various classes. To refer to the present show of the Royal Agricultural Society at Bedford, the official lists tell us of the vast number of agricultural implements entered for competition, the class of drills alone including 135 entries. Every one of these implements, before this article is in type, will have been carefully tested by actual work in the field ; the quantity of power required to produce a certain amount of work will have been ascertained by a dynamometer contrived expressly for the purpose ; the construction of each implement will have been thoroughly criticised; and finally, its merits in each department of its work will have been expressed by an elaborate system of marking. The reports of these trials will in due course appear in the Society's Journal, and the farmer will obtain a valuable mass of information on the subject of implements such as no private individual could have given him. Anyone who desires to see how thoroughly the work of judging is done, and what wonderful skill is now brought to bear on the construction of agricultural machines, should read the two reports on Portable Steam-engines and on Ploughs and Harrows in the last volume of the Royal Agricultural Society's Journal. There can be no question of the immense benefit resulting to practical agriculture from such exhibitions, and from the publication of such reports.

Anotherchiefitem in Agricultural Shows, and perhaps the most attractive, is the live stock. The non-agricultural public has seldom any notion of the points aimed at by an intelligent breeder of stock, and those who have never attended one of the country meetings of our great Agricultural Societies may very likely expect to see a mere collection of fat beasts. Our agricultural readers well know that this is far from being the case. Bulk is by no means the object which the breeder has in view; his aim is the production of an animal perfect both in form and quality, and fitted in the highest degree for the various purposes which it is intended to serve. The same principle is also steadily kept in view by the judges, who are instructed by the Society to form their decisions entirely on the animal's character for breeding purposes, and not on its present fitness for the butcher. We need

Vol. $\mathrm{x} .-\mathrm{No} .246$ hardly say that our Agricultural Shows have had a large share in that wonderful improvement of our various breeds of stock which has taken place to such a marked extent in recent years.

The subject of the varieties and breeds of cattle is full of interest ; indeed we hardiy know a more instructive field for the naturalist's study than that presented by the showyards of our Agricultural Societies. Here he will meet with abundant and striking instances of what may be effected by artificial selection persistently carried on with a definite purpose in view; and here also he will meet with equal evidence of the great influence of climate and other ill-understood conditions, which put a limit to the possible work of the breeder, and confine certain varieties to certain districts. That so small a country as Britain should have so many distinct breeds of sheep and cattle localised in different parts of the island is certainly remarkable, and the subject becomes more interesting when we find that in many cases these local breeds cannot be maintained true to their character if transported to other parts of the island. Thus we have in Lincolnshire a breed of sheep remarkable for their long glossy wool. Many attempts have been made to establish flocks of these sheep in other parts of England, but as far as we are aware the peculiar gloss of the wool has always disappeared after a few years.

The effect of external conditions on the character of an animal becomes still more apparent if, after making acquaintance with British sheep and cattle, the naturalist crosses the sea and pays a visit to a continental agricultural show. The British farmer who visited the Vienna Exhibition last year must have stared with wondcr at the collection of animals there displayed. He would probably regard with contempt the long-1 $c_{0.0}$ ed, woolly pig, with large and powerful snout, quite unlike the inhabitants of his own styes; but when he learnt that the Transylvanian pig spends its life in the forest, and in winter time has to grub for its food through a foot or more of snow, the British visitor would begin to perceive that the animal is really far better fitted for such a life than his own favourite "Berkshire;" and he would be prepared to hear that English pigs in such districts have proved a failure. Equally remarkable to an Englishman would appear the curious Merino sheep, bred entirely with a view to wool, but worthless considered as mutton, and the fine Hungarian draught oxen, admirably fitted for hard work and hard living, but which no amount of cake would turn into beef at two years old. These would be striking examples of the effect of artificial selection and natural conditions in producing different kinds of excellence from those aimed at in our own country.

In our autumnal shows the naturalist's attention might be directed with equal advantage to the infuence of cultivation on the characters of the various seeds and roots exhibited. It is not so very long ago that the first Swede and the first mangold were introduced into this country ; the varieties are now endless, and there is probably now quite as much difference between the roots originally imported and their modern representatives as between the greyhound-like swine one sees in old engravings and the present English examples of the race. Artificial selection has, in the case of roots and seeds, taken a wide scope, endeavouring to supply the very various wants of 
the farmer. Varieties suitable for early and late growth, and for various descriptions of soil and climate, are aimed at, and in many instances produced. The advantage of having a continual supply of new varieties appears in some cases to be considerable; thus in the case of the potato disease it seems generally acknowledged that a recently introduced kind resists disease far better than an old sort. Varieties cannot, however, as is well known, be trusted to maintain their character ; fresh seed must constantly be employed, and the process of selection must continually be maintained. The trade of the seedsman is thus one of never-ending use and importance. Perhaps one of the most striking recent instances of what may be effected by cultivation with a definite object is afforded by the case of sugar-beet. Beetroot contains somewhere about 8 per cent. of sugar; cultivation, however, and suitable manuring have so increased this percentage that sugar-beet now yields I2-14 per cent. of sugar in the average of seasons, and in favourable seasons 17 per cent. is sometimes reached. We need hardly point out that the practical influence of Agricultural Shows is again most useful in bringing under the farmer's notice both the new varieties raised in this country and the new species introduced from time to time abroad.

The Royal Agricultural Society has lately gone a step beyond the usual limits of the showyard, and has taken advantage of its country meetings to offer prizes for the best-managed farm in the surrounding district. This is undoubtedly a step in the right direction. Hitherto the teaching of the Agricultural Show has been pretty much confined to the subjects of live stock and implements. Certain portions of the farmer's work have been exhatistively illustrated; but farming as a whole has scarcely been dealt with. Might we suggest that the Royal Agricultural Society should go still further in carrying out its admirable motto, "Practice with Science," and cndeavour to make its colintry meetings yet more effective in diffusing true knowledge. Why shnuld not the Society arrange for two or three public lectures in the show-week, to be given by persons eminent in science or in practical agriculture? How much valuable teaching might thus be imparted. The Royal Agricultural Society has already exerted itself in the cause of scientific education for the sons of farmers, and has continued this worls in the face of considerable opposition; let it enlarge its good work still further, and aim at teaching the farmers who are anmually gathered at its Agricultural Shows.

\section{COLONIAL GEOLOGICAL SURVEYS II.--VICTORIA}

Geological Survey of Victoria-Report of Pregress. By R. Brough Smyth. (Melbourne, I874.)

I R. SMYTH must be a shrewd and clever person. 1 He has one of the most difficult tasks to performto persuade or cajole a Colonial Government or Assembly which knows nothing and cares still less about anything scientific, to vote money for a scientific object and to take some interest in having that object carried out. Not many years ago Victoria had a regular Geological Survey, equipped at the colony's expense and directed by Mr. Selwyn, who now so ably conducts the great Survey of Canada. For some reason which we have heard variously described, but which seems to have lain to some extent at least in official jealousies and in differences of opinion as to the degree in which geological research as opposed to mere mineral prospecting should guide the progress of work, the Victorian Survey came to an end and its officers were left to seek employment elsewhere. At the same time the Department of Mines in the colony showed great activity in collecting mining and geological information, the prime mover in this being the secretary, Mr. Brough Smyth. When the Geological Survey ceased to exist he seems to have thrown himself more into a geological line. With no little sagacity and tact he gradually organised a less ambitious scheme for having the country geologically surveyed. He obtained the services of one or two members of the previous Geological Survey, and, with a small grant from the legislature, began to make a geological examination of some of the mining districts, and to prepare maps and sections to show their structure. Under the wing of the Mining Depariment he evidently could do a good deal without placing a formal vote for a Geological Survey service on the colonial estimates.

How much soever a man may have science at heart, in such a population as that of Victoria he can hardly hope to find much encouragement for science pure and simple. It is needful for him to show some practical utility in his work before he can expect to receive aid, especially of a pecuniary kind. Fortunately in Victoria one great element in the national wealth lies in mining. Anything therefore which tends to increase the value of mines, or to lead to the discovery of fresh mineral fields, appeals at once to the feelings of the colonial legislators.

Mr. Smyth indeed in the present Report grows very bold, going even so far as to assert that the main object of the survey should be scientific discovery, any practical benefit arising from the work being a sort of secondary and accidental circumstance. He takes good care, however, to bring the practical benefits well into the foreground, so that imagine his superiors are not likely to quarrel with his theory so long as he adheres to his present practice. It would, indeed, be very short-sighted policy to interfere with him. $\mathrm{He}$ is unquestionabiy right in endeavouring to place the knowledge of the mineral structure of the colony on a sound basis of scientific exploration. There may perhaps be no apparent pecuniary return for the outlay at first, but the money expended as he is expending it will assuredly in the end be repaid tenfold. It will save a vast amount of expense in enabling colonists to decide where to begin their mineral ventures and in pointing out where no possible outlay could be profitable. It will stimulate the development of the mineral wealth of the country, and thus add directly and largely to the national prosperity.

We do not notice much of geological novelty in this Report of Progress, though some of the details are interesting, particularly in regard to fresh illustrations of the wonderful volcanic history of some of the goldfields, and to certain of the fossils which have been obtained in recent explorations. A list of all the fossil species hitherto obtained in the colony is inserted in the Report, and forms, so far as we know, the first list of the kind which Victoria has furnished. A considerable proportion of the species is from Upper or Lower Silurian rocks. A few are Devonian and Upper Palrozoic. With regard to Secondary and Tertiary rocks, Mr. Smyth very properly 